\title{
Role of Antidiabetic Compounds on Glucose Metabolism - A Special Focus on Medicinal Plant: Salacia sps
}

Deepak KGK, Nageswara Rao Reddy Neelapu and Surekha Challa*

Department of Biochemistry and Bioinformatics, GITAM Institute of Science, GITAM University, Rushikonda, Visakhapatnam, India

\begin{abstract}
Diabetes mellitus is one of the common metabolic diseases in the world associated with high blood sugar levels. Diabetes is categorized into type I and type II. The common type of diabetes is type II diabetes that is insulin dependent. On a global level, plant sources employed in traditional medicine are believed to be valuable to treat diseases. Ancient physicians had mastered the science of managing diabetes by balancing herbs or plants as food and medicine. Modern therapies are too costly to be practical for diabetic referrers. The ethanopharmacological use of herbal remedies for the treatment of diabetes is an area of study with a huge potential in the development of alternative, inexpensive therapies for treating the disease. The present paper reviews various traditionally used medicinal plants and their modes of action. Medicinal plants such as Anacardium occidentale, Coccinia indica, Gymnema sylvestre, Panax ginseng, Salacia spp. etc. with their active compounds such as salacinol, kotalanol, glucoside jamboline, phytol, myoinositol, scyllitol, pryones, stigmat-4-en-3-one, cholest-4-en-3-one etc. showed antidiabetic activity. The different modes of action by these compounds include inhibition of intestinal amylase $\alpha$-glucosidase, increase of $\beta$-cell stimulation, increase in number of insulin receptors, increase in insulin receptor binding affinity to the released insulin, fighting against free radicals to decrease cell damage and decrease of hepatic glucose by decreasing gluconeogenesis and glycogenolysis.
\end{abstract}

Keywords: Diabetes; Glucose metabolism; Medicinal plants; Salacia

\section{Introduction}

Diabetes mellitus is the common endocrinal disorder and rapidly increasing disease in the human population all over the world [1]. It is estimated that around 150 million of the world population are victims of this endocrinal disorder. Diabetes often leads to complications such as peripheral neuropathy, retinopathy, coronary heart diseases and cataract [2]. The two types of diabetes are type I and type II. In type I diabetes, body does not produce insulin because of autoimmune destruction of insulin producing $\beta$-cells of the pancreas. As a result the glucose levels in the blood stream are increased. As this is predominantly seen in children and young adults, it is also known as juvenile diabetes. It is manifested by impaired glucose metabolism due to total loss of insulin after destruction of pancreatic $\beta$-cells and is also known as insulin-dependent diabetes mellitus (IDDM) [3]. Type II diabetes is the predominant type of diabetes, in which the body does not produce sufficient amounts of insulin or in some cases the body is resistant to insulin or target tissues are insensitive to insulin. This type of diabetes is also known as non-insulin-dependent diabetes mellitus (NIDDM) [4]. The cause of diabetes is a mystery although both genetic and environmental factors such as obesity and lack of exercise appear to play a role.

The recommended drugs for diabetes treatment are sulphonylureas and glibenclamide. These are chemically synthesized insulin secretagogues. $\beta$-cell membrane potential controls secretion of insulin. It depends on the activity of ATP-sensitive $\mathrm{K}^{+}$channels in the plasma membrane. Increase in the cytoplasmic ATP/ADP ratio closes $\mathrm{K}^{+}$ channels. This leads to depolarization of cell membrane that leads to the opening of voltage-dependent calcium channel and it eventually results in an increase in the intracellular calcium and thereby stimulating the $\beta$-cells of pancreas to release insulin [5]. Chemically synthesized drugs are not preferred because of the high mortality rates witnessed in the patients suffering with diabetes. Therefore, focus has shifted on to biosynthetically manufactured insulin that is being administered to IDDM and NIDDM patients, referred to as insulin therapy. Complications associated with insulin therapy are mode of administration of insulin, dose of insulin, the timing of administration of insulin etc. The various side effects include insulin allergy, lipodystrophy and lipoatropy, altered metabolic control, insulin antibodies, placental transfer of insulin antibodies, autoimmunity and also other late complications such as morphological changes in kidneys and severe vascular complications [6]. Therefore the trend is now on usage of herbal medicine and it can be a promising substitute to the chemical drugs and insulin therapy.

Plants are believed to be the world's best chemist and are non-toxic than the chemical drugs. Many higher plants are the major sources of natural products (secondary metabolites) such as terpenes, alkaloids, cardiac glucosides etc. of pharmaceutical importance.

The present treatment of diabetes with medicinal plants is focused on controlling and lowering blood glucose by:

- Stimulating $\beta$-cells of pancreatic islet to release insulin

- Increasing insulin receptors

- Decreasing gluconeogenic enzymes, thereby maintaining blood glucose levels

- Inhibiting enzymes responsible for increased blood glucose levels

- Fighting against free radicals and decreasing cell damage

A total of 306 species have been reported for the treatment of

${ }^{*}$ Corresponding author: Surekha Challa, Associate Professor, Department of Biochemistry and Bioinformatics, GITAM Institute of Science, GITAM University, Rushikonda, Visakhapatnam- 530045. AP, India, Tel: +91-891-2840464; Fax: +91891-2790032; E-mail: challa surekha@gitam.edu

Received January 29, 2014; Accepted March 25, 2014; Published March 27 2014

Citation: Deepak KGK, Nageswara Rao Reddy N, Surekha C (2014) Role of Antidiabetic Compounds on Glucose Metabolism - A Special Focus on Medicinal Plant: Salacia sps. Med chem 4: 373-381. doi:10.4172/2161-0444.1000168

Copyright: (c) 2014 Deepak KGK, et al. This is an open-access article distributed under the terms of the Creative Commons Attribution License, which permits unrestricted use, distribution, and reproduction in any medium, provided the original author and source are credited. 
diabetes, a few of them namely Anacardium occidentale, Coccinia indica, Gymnema sylvestre, Panax ginseng, Salacia spp. are reviewed with their mode of action.

\section{Activity Based on Stimulation of $\beta$-Cells of Islets of Pancreas}

After high carbohydrate meal, glucose levels are increased. Rising blood glucose levels (above $5 \mathrm{mM}$ ) trigger, initiate and secrete insulin from $\beta$-cells of pancreas. $\beta$-cells have a large number of glucose transporters (GLUT 2) that permit influx of glucose. It is important to sense glucose levels and helps in adjusting the levels of insulin. Glucose is immediately phosphorylated to glucose -6- phosphate and the increased phosphorylation of glucose leads to rise in ATP:ADP ratio thereby inactivating potassium channels which depolarize the membrane causing the potassium channels to close and calcium channels to open up. Calcium channels open up allowing calcium ions to flow inward and this rise in calcium levels leads to translocation of multiple intracellular vesicles to the cell membrane and exocytotic release of insulin (Figure 1).

Insulin produced in $\beta$-cells of pancreas is secreted into the blood, circulates in unbound form and reaches liver, muscles and kidney to maintain blood glucose levels. Insulin levels are maintained by its short half-life ( 6 minutes) or by getting cleared (within 10-15 minutes) by enzyme insulinase in liver, muscles and kidney. Insulin initiates cellular responses by binding to cellular receptor, a transmembrane glycoprotein composed of two alpha and two beta-subunits. Alphasubunits are for binding of insulin and beta-subunits for signal transduction with insulin-stimulated tyrosine kinase activity. When an insulin molecule attaches to the alpha subunit of insulin receptor, signal is propagated to beta subunit and it by itself gets autophosphorylated, activating tyrosine kinase to phosphorylate multiple other intracellular enzymes including a group of insulin receptor substrates. Binding of insulin to the receptor increases the uptake of glucose into cell by $80 \%$. The increase in glucose intake is by translocation of vesicles to the cell membranes, these vesicles carry multiple molecules of glucose transporters (GLUT4) that bind to the cell membrane and enables glucose uptake into the cells. Increase in glucose absorption, causes rapid uptake of glucose by muscles for future use, rest is stored as glycogen.

Progressive $\beta$-cell dysfunction in type II diabetes leads to loss of $\beta$-cell area, islet number and changes in profile of islet cell distribution. Unavailability or decreased number of insulin molecules either show impaired function of initiation or secretion of insulin from $\beta$-cells of pancreas and subsequent increase of blood glucose levels. Herbal extracts help in overcoming progressive $\beta$-cell dysfunction by increasing and maintaining $\beta$-cell number [7]; thereby allowing insulin to initiate and secrete insulin from $\beta$-cells. Increased insulin levels in turn control blood glucose levels. The herbal extracts of Gymnema sylvestre, Anacardium occidentale and Panax ginseng stimulate the $\beta$-cells, increase affinity of insulin binding receptor to insulin and maintain optimum sugar levels in the body.

\section{Gymnema sylvestre}

Gymnema sylvestre has a key role in ayurvedic medicine. It is a large woody climber plant belonging to Asclepiadaceae family. It is native to central India, western India, tropical Africa and Australia. The leaves contain resins, albumins, carbohydrates, tartaric acid [8-11] and gymnemic acid (a glucoside with anti-saccharine property) [8].

The extracts of $G$. sylvestre increase $\beta$-cell number, increase insulin release by increasing cell permeability to insulin and there by showing effect on functioning of pancreatic $\beta$-cells. The glycosylation of both haemoglobin and plasma proteins is significantly greater in the

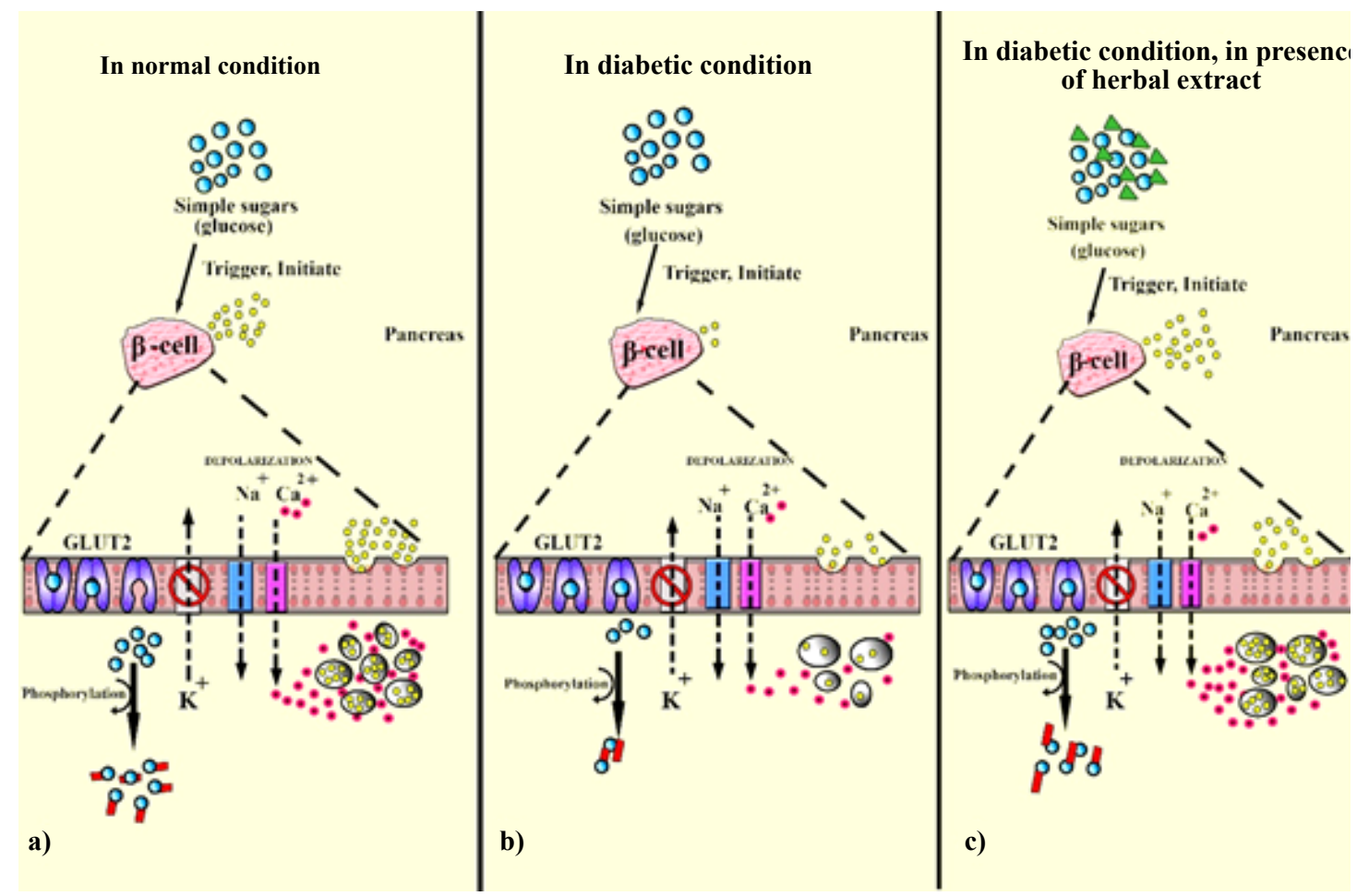

Figure 1: Schematic representation of release of insulin when glucose is sensed in the blood in different conditions a) Normal b) Diabetic c) Diabetic treated with herbal extract. 
diabetic patients and it interferes with erythrocyte function resulting in decreased oxygen delivery to critical tissues. This critical condition is reversed by using the extracts of G. sylvestre [12]. G. sylvestre decreased fasting blood glucose levels in alloxan diabetic rats due to the increase in the activity of enzymes responsible for utilization of glucose by insulin-dependent pathway or by regenerating the $\beta$-cells of islets of pancreas [13]

Chatterji [14] has isolated a high molecular weight compound Om Santal Adivasi (OSA). OSA stimulated insulin secretion from the mouse MIN6 $\beta$-cell line in in vitro conditions without exerting an effect on $\beta$-cell viability and membrane integrity. OSA showed mean reduction in fasting and post-prandial blood glucose by significantly increasing the circulation of insulin and C-peptide when administered before food intake for 60 days [15].

\section{Anacardium occidentale}

Anacardium occidentale, commonly known as cashew belongs to the family Anacardiaceae. It is an evergreen tree growing $10-12 \mathrm{~m}$ height with a short, irregular shaped trunk. The bark and leaves are of medicinal importance as they show anti-diabetic, anti-inflammatory, astringent [16] and anti-microbial activity [17]. Two active principles from bark namely, cholest-4-en-3-one and stigmast-4-ene-3one showed anti-diabetic activity [18]

On the other hand, it is also known to block the enzyme pyruvate carboxylase which plays a major role in gluconeogenesis and thus decreasing the glucose output levels [18]. The herbal extract increases the glucose uptake into the muscles by increasing glucose transport activity and increased glucose utilization by the peripheral tissues and thereby maintaining the blood glucose levels $[19,20]$. Stigmast 4-en3 -one showed greater hypoglycemic effect on fasting blood glucose concentration but cholest-4-en-3-one produced more significant reductions in postprandial glucose concentrations. The difference in hypoglycemic activity may be related to the structural difference where ethyl group is absent at C-24 in cholest-4-en-3-one but present in stigmast 4-en-3-one [21].

\section{Panax ginseng}

Panax ginseng belonging to family Araliaceae is mainly used to maintain the whole-body glucose homeostasis of the body. The pharmacological efficacy includes anti-diabetic, anti-oxidative, antiaging, improved brain function, pain-relieving, anti-tumor, enhanced liver function, anti-fatigue, anti-stress and improved sexual functions [22]. The extracts of all parts of $P$. ginseng (roots, stems, leaves and fruits) stimulate insulin secretion and insulin-like substances which decrease high blood glucose levels.
There are several hypothesis relating to the lowering of blood glucose levels by the herbal extract of $P$. ginseng. It includes modulator effect on the release of gastric juice in the stomach which results in the slow digestion of food resulting in the decreased rate of carbohydrate absorption and thereby slow release of sugars into the blood. It is also known to increase the blood insulin level and glucose stimulated insulin secretion in diabetic mice. It may affect the glucose transport by activating the translocation of GLUT- 4 glucose transporters mediated by nitric oxide $[23,24]$.

\section{Activity based on increasing insulin receptors}

Insulin receptor is a transmembrane receptor that is activated by insulin and plays a key role in the regulation of glucose homeostasis, a functional process. Insulin receptor under degenerate conditions may result in diabetes and cancer.

The mechanism of lowering the blood glucose levels by the herbal extracts of Anacardium could be similar to pancreatic hyperglycemic mechanism of sulphonylurea and glibenclamide that are used as standard drugs to treat diabetes. The herbal extract directly stimulates the $\beta$-cells of pancreas which results in an increased release of insulin, increase the number of insulin receptors and insulin receptor binding affinity [18] (Figure 2).

\section{Activity Based on Decrease in Gluconeogenic Enzymes}

The common abnormality associated with type II diabetes is increased endogenous production of glucose in the body. Studies by Magnussson et al., Wajngot et al. and Basu et al. [25-27] suggest that gluconeogenesis in liver is largely responsible for overproduction of glucose in fasting type-II diabetic patients. Enzymes such as fructose-1,6bisphosphatase and glucose-6-phosphatase of liver are the primary and secondary regulators that are known to play a major role in maintaining the blood glucose levels. Fructose-1,6-bisphosphatase is activated by citrate and potently inactivated by fructose 2,6 bisphosphate and AMP. The levels of fructose-6-bisphosphate are low during starvation and high in the fed state because of the antagonistic effects of glucagon and insulin. Glucose-6-phosphatase is allosterically controlled but its $\mathrm{Km}$ for glucose 6 phosphate is far higher than intracellular concentration of the metabolite. Therefore, gluconeogenesis and glycogenolysis are considered potential targets for pharmacological intervention as they play a major role in endogenous glucose production resulting in hyperglycemia (Figure 3). The other way of maintaining blood glucose levels in the body is by decreasing the hepatic gluconeogenesis enzymes that subsequently decreases hepatic gluconeogenesis. The herbal extracts of Coccinia indica are known for decreasing the hepatic gluconeogenesis with the help of hepatic enzymes.
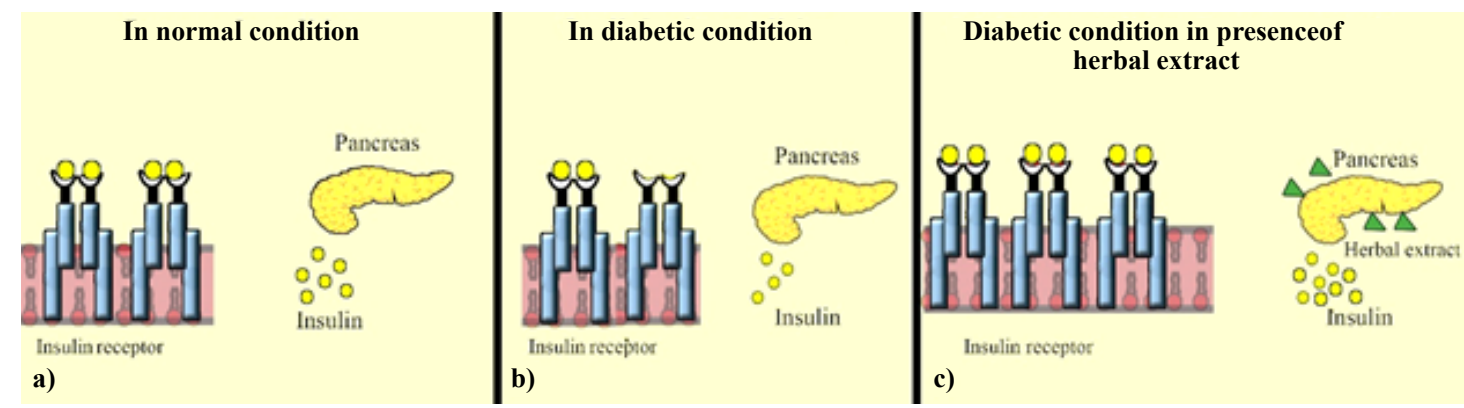

Figure 2: Schematic representation of stimulation of pancreas to release insulin and subsequent increase in number of insulin receptors in different conditions a) Normal b) Diabetic c) Diabetic treated with herbal extract. 


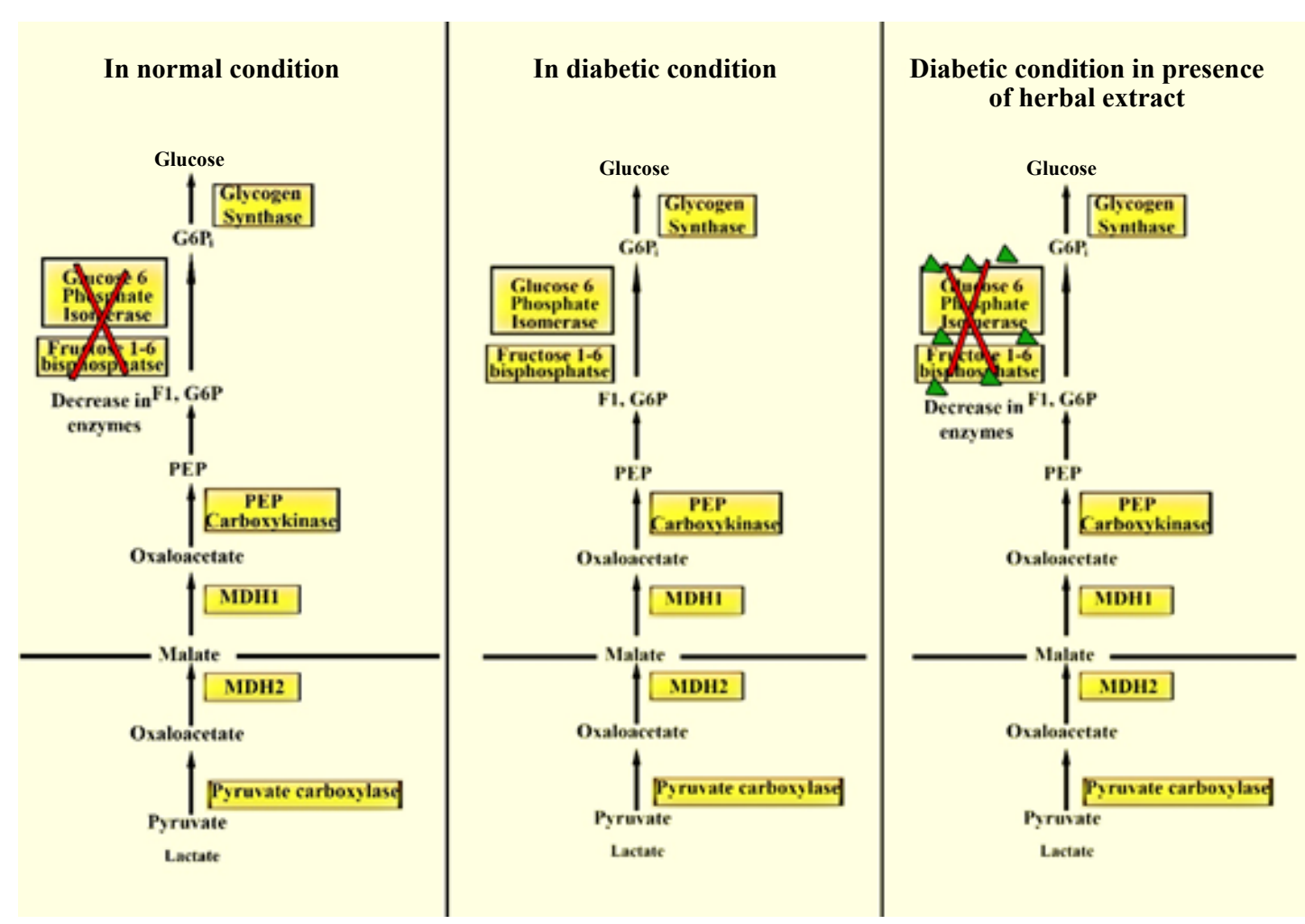

Figure 3: Schematic representation of maintenance of gluconeogenic enzyme levels in different conditions a) Normal b) Diabetic c) Diabetic treated with herbal extract.

\section{Coccinia indica}

Coccinia indica is a climbing perennial herb of Cucurbitaceae family and is distributed widely all over India. The plant has been used since ancient times for treating diabetes mellitus in the Indian system of medicine known as ayurveda.

The leaf extracts of $C$. indica were assayed to understand the mechanism of the hypoglycemic effect of enzymes glucose-6phosphatase and fructose-1,6-bisphosphatase of liver, as they play a major role in maintaining the blood glucose levels. Leaf extracts significantly reduced the hepatic glucose-6-phosphatase and fructose1-6-bisphosphatase levels by $32 \%$ and $30 \%$ respectively in the streptozotocin induced diabetic rats. A $19 \%$ decrease was observed in the normal fed controls, thus suggesting that the leaf extracts decrease hepatic gluconeogenesis and thereby reducing the blood glucose levels [28]. Aqueous suspension of $C$. indica leaves (60\% ethanolic extract) administered with oral dosage $(200 \mathrm{mg} / \mathrm{Kg}$ weight $)$ lowered blood glucose in streptozotocin (65 $\mathrm{mg} / \mathrm{Kg}$ body weight) induced Wistar albino rats (diabetic) and normal rats (18 hrs fasted) by $27 \%$ and $23 \%$ respectively. Pectin, the active principle present in the seed of $C$. indica when administered orally at a dosage of $200 \mathrm{mg} / 100 \mathrm{~g}$ showed simultaneous significant hypoglycemic activity and an increased level in liver glycogen by interfering with carbohydrate metabolism [29]. The anti-hyperglycemic effects of the extract could lower intracellular cyclic AMP that is responsible for gluconeogenic effect of the pituitary gland [30].

\section{Activity based on Fighting against Free Radicals to Decrease Cell Damage}

Reactive oxygen species (ROS) produced during hyperglycemic conditions play a key role in developing secondary complications of diabetes [31]. Free radicals are produced by autoxidation reaction. It includes oxidation of sugars and sugar adducts to protein and by autoxidation of unsaturated lipids in plasma and membrane proteins, the possible sources of oxidative stress and damage to proteins in diabetes. The oxidative stress may also be magnified and propagated by a continuing cycle of metabolic stress, damage of tissue, and death of cell. This leads to increased free radicals production and compromised inhibitory and scavenging systems. Increased oxidative stress in diabetes can be due to increased nonenzymatic glycosylation (glycation), autoxidative glycosylation, stress resulting from changes in energy metabolism, alterations in sorbitol pathway activity, changes in the level of inflammatory mediators ( $\beta$-cells) and the status of antioxidant defense systems, and localized tissue damage resulting from hypoxia and ischemic reperfusion injury [32]. The amount of damage to the tissue is the outcome of the balance between the generated free radicals and the antioxidant defense system [33].

In diabetes mellitus, high glucose levels inactivate antioxidant enzymes such as superoxide dismutase (SOD), glutathione peroxidase and catalase (CAT) by glycating the proteins [34]. $\beta$-cells are particularly sensitive to ROS because $\beta$-cells are low in free radical quenching enzymes (SOD, CAT, glutathione) leading to damage of mitochondria and death of $\beta$-cells [35].

Methanolic extracts of Terminalia chebula, Terminalia belerica and Emblica officinalis are being used in Indian system of medicine. The antioxidant compounds found in T. belerica, T. chebula and E. officinalis are gallic acid and its derivatives. The extracts of these plants have a property of scavenging hydroxyl and superoxide radicals (Figure 4) [36]. Further in vivo studies using aqueous ethanolic root extract of Berberis aristata showed hypoglycemic effect and antioxidative 
activity in alloxan induced diabtes rats [34]. Thus, supplementing diet of diabetic patients with antioxidants prevents $\beta$-cells damage and control diabetes.

\section{Activity Based on Inhibition of Enzymes}

Alpha-glucosidases, the intestinal enzymes found in the brush border of small intestine, play an important role in breaking down complex carbohydrates to glucose and other monosaccharides. Alphaglucosidase inhibitors are saccharides that act as competitive inhibitor to the enzyme $\alpha$-glucosidase, needed for digesting carbohydrates and thus maintain hypoglycemic condition. Enzyme aldose reductase catalyzes the NADPH-dependent conversion of glucose to sorbitol (sugar alcohol) in glucose metabolism. In diabetic condition aldose reductase activity increases with a rise in glucose concentration in tissues that are not insulin sensitive (lenses, peripheral nerves and glomerulus). Sorbitol does not diffuse through cell membranes as the membranes are impermeable to sugar alcohols easily and therefore accumulation of sorbitol leads to osmotic damage. Osmotic stress on cells may lead to long term complications like retinopathy and neuropathy. Aldose reductase inhibitors competitively bind to the enzyme aldose reductase

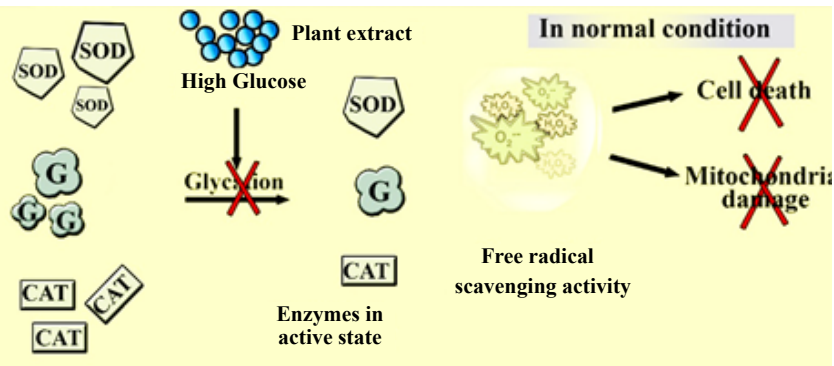

SOD-Superoxide dismutase; G-Glutathione peroxidase; CAT-Catalase
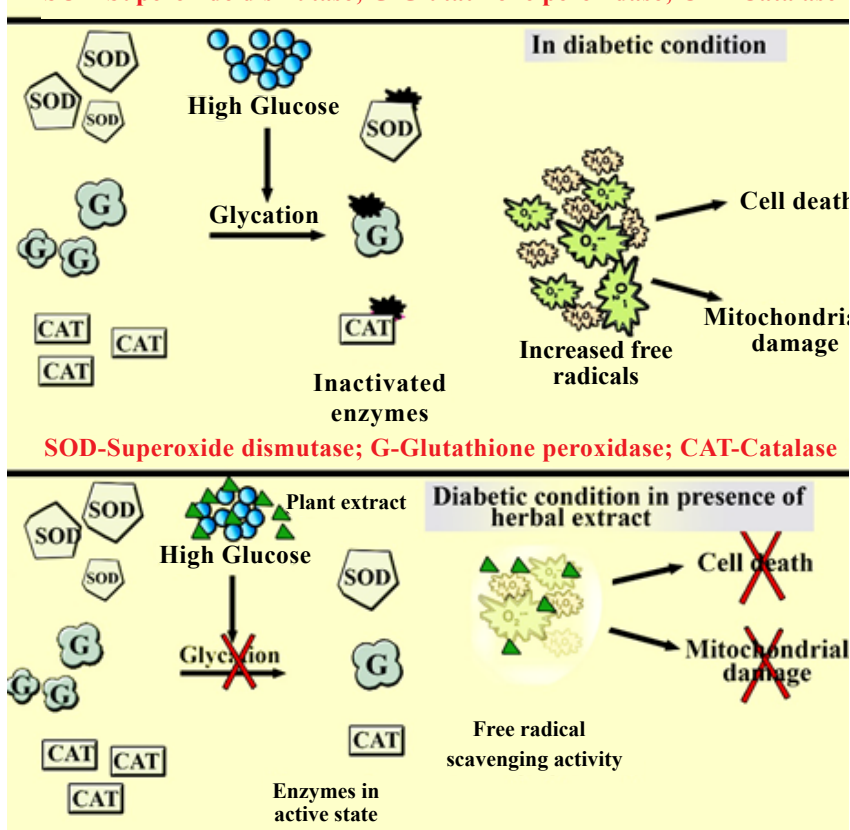

SOD-Superoxide dismutase; G-Glutathione peroxidase; CAT-Catalase

Figure 4: Schematic representation based on fight against free radicals to decrease cell damage.

a) Normal b) Diabetic c) Diabetic treated with herbal extract.

In normal condition free radicals are scavenged by the enzymes, in diabetics,

due to glycation of enzymes free radicals are not scavenged, in diabetics

treated with herbal extract show better radical scavenging activity. and prevent accumulation of sugars in the sensitive areas like eyes and thereby prevent cataract formation. The herbal extracts of Salacia spp. competitively bind to the enzymes ( $\alpha$-glucosidases and aldose reductases) and prevent the breakdown of carbohydrates into simple sugars thereby maintaining blood glucose levels (Figure 5).

The genus Salacia are woody climbers of the Celastraceae family. These are naturally found in the Southern regions of India and Sri Lanka. Salacia genus is composed of more than 20 species among which S. oblonga, S. reticulata, S. macrosperma, S. chinensis, S. brunoniana, S. fruticosa, S. prenoides, S. madagascariensis, S. liana, S. kraussi etc. are having medicinal value (Table 1). Some species of Salacia demonstrated antidiabetic [37] and hypoglycemic activity.

The active principles including secondary metabolites (salacinol, kotalanol and kotalagenin 16-acetate) phenolic compounds, terpenes (sesquiterpenes and triterpenes) and sugars (dulcitol, D-fructose, D-glucose, sucrose, galactinol, 3-O- $\alpha$-D-galactopyranosyl (1-6)-O- $\beta$ D-galactopyranosyl-sn-glycerol, raffinose and stachyose) [2] possessed potent antidiabetic activity. Other compounds such as mangiferin [38], catechins and tannins inhibit lipid metabolizing enzymes [39].

\section{Salacia oblonga wall}

Salacia oblonga Wall is a small glabrous tree or shrub. Leaves are 3-6 inches, elliptic-oblong, rounded at apex or with short obtuse acumen, slightly serrate, subcoriaceous and leaves turn yellow when dry. Flowers are sessile in the leaf axils, petals are elliptic; serrate and fruits are light brown in color.

S. oblonga Wall, commonly known as 'Ponkoranti' due to its characteristic golden yellow coloured roots. Roots of Salacia are widely used in ayurvedic system of traditional Indian medicine as a remedy for various diseases like diabetes, gonorrhea, rheumatism, itching, asthma, ear diseases and inflammations $[2,40]$.

S. oblonga contains two potent $\alpha$-glucosidase inhibitors: salicinol and kotalanol [2] the potent therapeutic agents that are used in treatment of carbohydrate-metabolic disorders such as diabetes mellitus. The aqueous extract showed significant hypoglycemic activity [37]. Herbal extract of S. oblonga bind to the intestinal enzymes such as a-glucosidases that are in involved in breaking down of carbohydrates, oligosaccharides (disaccharides-sucrose and trisaccharides-maltose) into monosaccharides (glucose and mannose). Therefore the binding of herbal extract to the enzyme rather than to a carbohydrate results in less amounts of glucose being released into the blood stream, thereby maintaining optimum levels of glucose in the blood [41]. It also showed inhibitory activity on aldose reductase that is responsible for chronic diabetic complications such as peripheral neuropathy, retinopathy and cataracts.

Bhagyajyothi et al. [42] evaluated the effect of standardized hydroalcoholic root extract of $S$. oblonga on the glucose levels in the blood. Insulin, blood glucose levels, triglycerol and fatty acids were assayed to understand the effect of herbal extract. Wistar albino rats are divided into 5 groups containing 8 rats in each group (normal control, streptozotocin induced control diabetic rats, diabetic rats with dosage of $100 \mathrm{mg} / \mathrm{Kg}$ of the herbal extract, diabetic rats with dosage of $50 \mathrm{mg} / \mathrm{Kg}$ of the herbal extract, diabetic rats with dosage of $500 \mu \mathrm{g} /$ $\mathrm{Kg}$ of the glibenclamide). Strepotozotocin was used to induce diabetes. Oral dosage of 50 and $100 \mathrm{mg} / \mathrm{Kg}$ of hydroalcoholic root extract was administered to the diabetes induced albino rats. The extract showed $44 \%(295.75 \pm 69.70 \mathrm{mg} / \mathrm{dl})$ and $45 \%(292.13 \pm 25.32 \mathrm{mg} / \mathrm{dl})$ decrease 


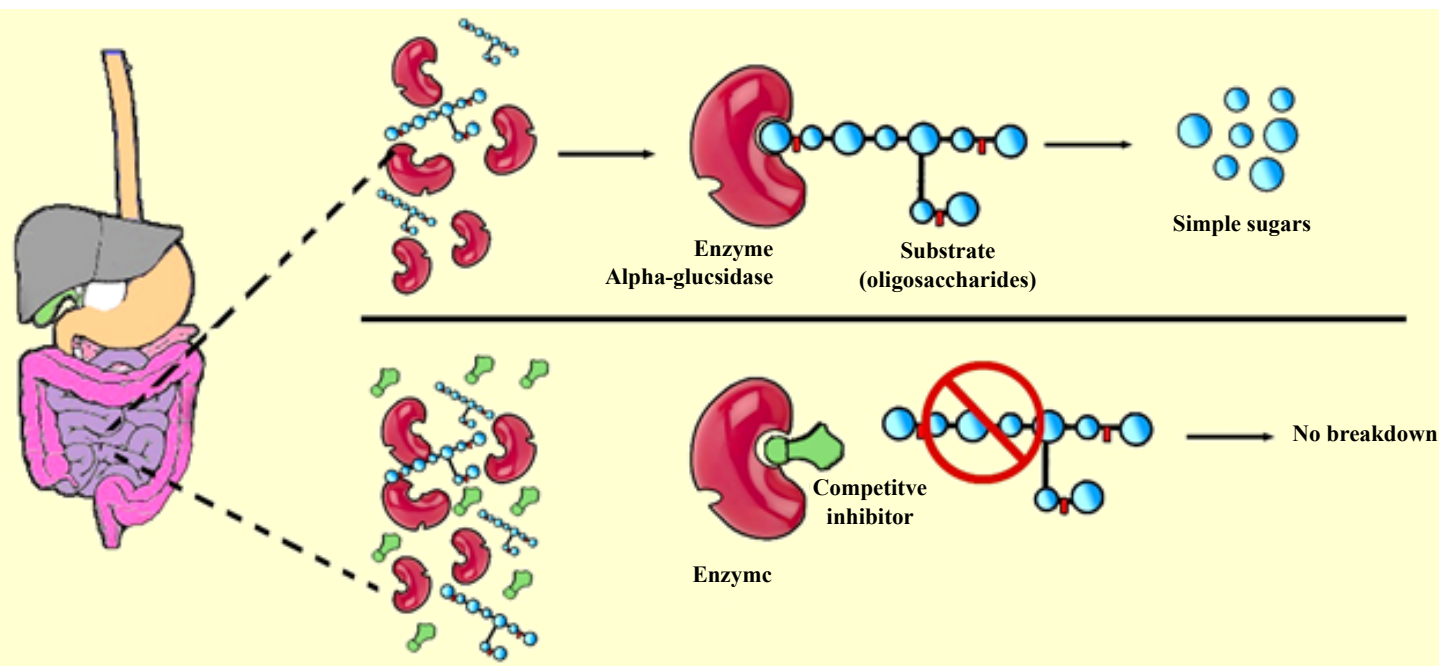

Figure 5: Schematic representation for a) breakdown of oligosaccharides to simple sugars by intestinal amylase b) blocking of intestinal amylase by herbal extract (competitive inhibitor) preventing breakdown of oligosaccharides to simple sugars.

\begin{tabular}{|c|c|c|c|c|}
\hline SI.No. & Name of the plant & Geographic Location & Medicinal properties & References \\
\hline \multirow{5}{*}{1} & \multirow{5}{*}{ S. oblonga } & \multirow{5}{*}{ India and Sri Lanka } & Antidiabetic & {$[2,4,31,37,39,56-59,61]$} \\
\hline & & & Anti-inflammatory & [62] \\
\hline & & & Antilipidemic & [63] \\
\hline & & & Cardiovascular & {$[59,64]$} \\
\hline & & & Antiperoxidative & [59] \\
\hline \multirow{3}{*}{2} & \multirow{3}{*}{ S. reticulata } & \multirow{3}{*}{ Tamil Nadu, India } & Antidiabetic & {$[33,65-69]$} \\
\hline & & & Antilipidemic & {$[43,70]$} \\
\hline & & & Anti-inflammatory & [35] \\
\hline \multirow{2}{*}{3} & \multirow{2}{*}{ S. macrosperma } & \multirow{2}{*}{ Western Ghats, India } & Antidiabetic & [71] \\
\hline & & & Antimicrobial & [72] \\
\hline 4 & S. chinensis & India & Antidiabetic & {$[46,73,74]$} \\
\hline 5 & S. brunoniana & Maharashtra, India & - & - \\
\hline 6 & S. fruticosa & Kerala, India & Antidiabetic & [75] \\
\hline 7 & S. prenoides & India & Antidiabetic & [76] \\
\hline 8 & S. madagascariensis & India & Antileukemic & [40] \\
\hline 9 & S. hainanensis & China & Antidiabetic & {$[77-79]$} \\
\hline 10 & S. petenensis & Central America & Antibacterial & {$[80]$} \\
\hline 11 & S. beddomei & Kerala, India & Antibacterial & [81] \\
\hline 12 & S. cordata & Bolivia & - & http://eol.org/pages/5227269/details \\
\hline 13 & S. crassifolia & Brazil & - & http://eol.org/pages/5227587/details \\
\hline 14 & S. impressifolia & Missouri, South America & - & http://eol.org/pages/5227808/details \\
\hline 15 & S. alwynii Mennega & Venezuela & - & http://eol.org/pages/11912502/details \\
\hline 16 & S. elliptica & Brazil & - & http://eol.org/pages/6940890/details \\
\hline 17 & S. gerrardii & South Africa & - & http://eol.org/pages/6940922/details \\
\hline 18 & S. grandifolia & Brazil & - & http://eol.org/pages/5227791/details \\
\hline 19 & S. lehmbachii & Nigeria & - & http://eol.org/pages/6940982/ details \\
\hline 20 & S. arborea & Brazil & - & http://eol.org/pages/11912503/details \\
\hline
\end{tabular}

Table 1: List of Salacia spp., geographic location and its medicinal properties.

in the blood glucose level when treated with $50 \mathrm{mg} / \mathrm{Kg}$ and $100 \mathrm{mg} /$ $\mathrm{Kg}$ herbal extract respectively. This decrease suggests that $50 \mathrm{mg} / \mathrm{Kg}$ of extract of dose could be the threshold level. Along with the decrease in blood glucose with $50 \mathrm{mg} / \mathrm{Kg}$ herbal extract, there is an increase in insulin levels in all the treated animals. The increased insulin levels were almost equal to glibenclamide treated animal group suggesting that the extract may stimulate insulin secretion from the $\beta$-cells of pancreas or it may regenerate $\beta$-cells of pancreas. On the other hand, significant decrease in cardiac triglycerol and fatty acid contents showed that extract prevent hyperglycemia and hypoinsulinemia.
Augusti et al. [43] used solvents like petroleum ether, chloroform, acetone, methanol and water to extract active principles from dried bark of S. oblonga. Experimental rats are divided into 3 groups (diabetic control, diabetic rats with herbal extract and glibenclamide administered group). Streptozotocin was used to induce diabetes to the experimental rats. The soluble acetone fraction tested on diabetic rat's decreased blood sugar by $25 \%$. Petroleum ether extract $(250 \mathrm{mg} / \mathrm{kg})$ also showed hypoglycemic activity in the experimental rats.

Hypoglycemic action of $S$. oblonga and tolbutamide $(200 \mathrm{mg} / \mathrm{Kg}$ 
body weight) were assayed using fasting albino rats. Dosage of $250 \mathrm{mg} /$ $\mathrm{Kg}$ body weight of herbal extract was administered to the test group. Chloroform fraction showed significant decrease in the blood glucose level with $60 \%$ potency of tolbutamide during $4 \mathrm{hrs}$ period. The long term activity of acetone fractions of Salacia are compared with the glibenclamide and insulin for a period of one month [43].

Faizal et al. [44] evaluated ayurvedic medicine 'Rajanyamalakadi' containing a mixture of Curcuma longa, Emblica officinalis and Salacia oblonga in type II diabetic patients (streptozotocin induced). Rajanyamalakadi (500 mg) showed significant antidiabetic, hypolipidemic and antioxidant effects due to the presence of terpenoids or curcuminoids or polyphenols or flavonoids.

S. oblonga extract increased glucose uptake in L6 rat myotubes by increasing glucose transporter 4. S. oblonga extract and mangiferin may exert antidiabetic effect by increasing glucose transporter 4-mediated glucose expression and translocation in muscle cells. These effects are probably mediated through two independent pathways that are related to $5^{\prime}$-AMP-activated protein kinase and PPAR-[45].

The above experiments suggest that extracts of $S$. oblonga in various forms-hydroalcoholic root extract, aqueous extract, acetone, choloroform fraction and mixture of C. longa, E. officinalis and S. oblonga have antidiabetic activity.

\section{Salacia reticulata}

S. reticulata is a climbing, perennial woody plant. The roots and stem are used in the ayurvedic system of medicine. Tezuka et al. [46] and Yoshikawa et al. [39] isolated active principles such as Salcinol and kotalanol from $S$. reticulata. These active principles showed a-glucosidase inhibiting activity whose mode of action was almost similar to that of S. oblonga.

Rajashree et al. [47] used a mixture of S. reticulata and Catharanthus roseus $\mathrm{L}$ and studied hypoglycemic and hypolipidemic effects. Wistar strain albino rats of both the sexes were divided into 4 groups: normal control rats, diabetic control rats, insulin treated (2-4 units $\mathrm{Kg} /$ body weight/day) and diabetic rats (streptozotocin induced with $50 \mathrm{mg} /$ $\mathrm{Kg}$ ). Results showed that there was a significant increase in the fasting blood glucose levels in controls but in the case of herbal formula treated diabetic rats, the blood glucose levels decreased when compared to diabetic controls. The possible mechanism to maintain blood glucose levels can be due to the inhibition of a-glucosidase, aldose reductase and pancreatic lipase enzymes. The herbal extract of $S$. reticulata may even act at the level of receptors (peroxisome proliferator-activated - alpha mediated lipogenic gene transcription and angiotenin II/ angiotensin II type 1 receptors). Yoshikawa [39] observed antiobesity effects in rats with hot water soluble fractions of $S$. reticulata roots.

Kishino et al. [48] used a mixture of S. reticulata aqueous extract and cyclodextrin (SRCD) to study the effects on obesity. Female C57BL/6J mice and male Sprague-Dawley rats obtained from Japan SLC were divided into normal, high fat diet administered, 0.2\% SRCD and $0.5 \%$ SRCD groups. The tests showed elevation of plasma triacylglycerol levels that were induced by oral administration of high fat liquid diet. The concentration of plasma triacylglycerol was decreased in the rats treated with $S$. reticulata mixture than in the control rats that are fed with high liquid fat [49].

Im et al. [38] studied the possible mechanisms of S. reticulata stems using KK-Ay diabetic mice. Findings suggested that mangiferin present in the aqueous extracts of $S$. reticulata showed a direct effect on the liver cells. Mangiferin also down regulated the gluconeogenic pathway by regulating the expression of fructose-1,6-bisphosphatase which is responsible for decreasing the fasting blood glucose levels in mice.

\section{Salacia chinensis}

S. chinensis is a small erect or straggling tree or large, woody, climbing shrub found throughout India including Andaman and Nicobar Islands. S. chinensis as a tonic is used to purify blood and to treat amenorrhea and dysmenorrheal. Root bark (aqueous, oil or powdered decoction) is used to treat diabetes, gonorrhoea, rheumatism, kin diseases, itches, asthma, thirst and ear diseases [50,51].

The phytoconstituents of the roots are alkaloids; glycosides; polyphenols; flavonoids; coumarins; proteins; carbohydrates; gums and mucilage; fixed oil and volatile oil etc. Triterpenoids such as lupanes, hopanes, friedelanes are abundant in root and stem of plant. Salacinol and mangiferin are the two main active principles that are known to show hypoglycemic activity. Salacinol isolated from the stems is a a-glucosidase inhibitor. It competitively binds to an enzyme instead of a carbohydrate source thus maintaining lower blood glucose levels in the body. Mangiferin called as C-glucosyl xanthone [52,53], 2-â-D-glucopyranosyl-1, 3,6,7-tetrahydroxy xanthone is used to treat immunodeficiency disorders such as diabetes, hepatitis, arthritis, cardiac and mental disorders [54]. Mangiferin also showed inhibitory effect on rat lense aldose reductase [34].

\section{Current Status of Medicinal Plants in Treating Diabetes}

Plant or plant products are the potential source of anti-diabetic drugs. Indian ayurvedic system of medicine, traditional Chinese medicine use plants to treat diabetes [4,55].

Indian medicinal plants having diabetic activity are Allium cepa, Allium sativum, Aloe vera, Cajanus cajan, Coccinia indica, Caesalpinia bonducella, Ficus bengalenesis, Gymnema sylvestre, Momordica charantia, Cinnamon Ocimum sanctum, Pterocarpus marsupium, Swertia chirayita, Syzigium cumini, Tinospora cordifolia and Trigonella foenum graecum [55]. Plants such as Allium cepa, Allium sativum, Coccinia indica, Cajanus cajan, Momordica charantia and Trigonella foenum graecum are part of regular diet for Indians and help in regulating glucose metabolism.

Momordica charantia lowers blood glucose levels and controls diabetes. It also helps in increasing pancreatic insulin secretion and preventing insulin resistance. Cinnamon has the ability to lower blood sugar levels by stimulating insulin activity. It improves glucose tolerance and lowers blood sugar levels due to its hypoglycemic activity. It also stimulates the secretion of glucose dependent insulin, and slows down the absorption of carbohydrates as it is rich in fiber. Emblica which is rich in vitamin $\mathrm{C}$, promotes proper functioning of pancreas. Black plum or jambul rich in anthocyanins, ellagic acid, hydrolysable tannins control blood sugar level. Aloe vera contains phytosterols that have anti hyperglycemic effects for type II diabetes. Curry leaves control diabetes by reducing the rate at which starch is broken down to glucose. Gauva rich in vitamin $\mathrm{C}$ and fiber maintain blood sugar levels by reducing sugar absorption; blood sugar levels and cholesterol in blood to improve health of diabetic patient. In addition, drinking 2.5 lts of water mobilizes the high sugar content and lowers the risk of ailments associated with diabetes [56-80].

The Chinese medicinal plants that are used in traditional medicine are Fructus arctii, Fructus xanthii, Radix polygalae, Radix puerariae, Radix panacis Quinquefolii, Fructus coini, Rhizoma atractylodis, Rhizoma anemarrhenae etc. are used for treating diabetes [4]. 
The Japanese medicinal plants used as medicine are Angelica keiskei, Echinops setifer Iljin, Lindera strychnifolia, Phellodendron amurense.

\section{Conclusion}

Medicinal plants such as Anacardium occidentale, Coccinia indica, Gymnema sylvestre, Panax ginseng, Salacia spp. are rich sources for active principles like salacinol, kotalanol and kotalagenin 16-acetate, phenolic compounds, terpenes (sesquiterpenes and triterpenes) and sugars (dulcitol, D-fructose, D-glucose, sucrose, galactinol, 3-O- $\alpha-\mathrm{D}$ galactopyranosyl (1-6)-O- $\beta$-D-galactopyranosyl-sn-glycerol, raffinose and stachyose). These herbal principles can be used to develop alternative, inexpensive therapies for treating and managing diabetes. The different modes of action include increase of $\beta$-cell stimulation; increase in insulin receptor binding affinity to the released insulin; decrease of hepatic glucose by decreasing gluconeogenesis and glycogenolysis; fighting against free radicals, inhibition of a-glucosidase and aldose reductase.

\section{Acknowledgments}

DKGK, NNRR and CS are thankful to the GITAM University, Visakhapatnam, India for providing the facility and support. CS is thankful to DST, New Delhi for the project funding SR/FT/LS-32/2010. DKGK is thankful to DST, New Delhi SR/FT/ LS-32/2010 for providing JRF fellowship.

\section{References}

1. Andrade-Cetto A, Heinrich M (2005) Mexican plants with hypoglycaemic effect used in the treatment of diabetes. J Ethnopharmacol 99: 325-348.

2. Matsuda H, Murakami T, Yashiro K, Yamahara J, Yoshikawa M (1999) Antidiabetic principles of natural medicines. IV. Aldose reductase and qlphaglucosidase inhibitors from the roots of Salacia oblonga Wall. (Celastraceae): structure of a new friedelane-type triterpene, kotalagenin 16-acetate. Chem Pharm Bull (Tokyo) 47: 1725-1729.

3. Atkinson MA, Maclaren NK (1994) The pathogenesis of insulin-dependent diabetes mellitus. N Engl J Med 331: 1428-1436.

4. Li Y, Peng G, Li Q, Wen S, Huang TH, et al. (2004) Salacia oblonga improves cardiac fibrosis and inhibits postprandial hyperglycemia in obese Zucker rats. Life Sci 75: 1735-1746.

5. Fuhlendorff J, Rorsman $\mathrm{P}$, Kofod H, Brand CL, Rolin B, et al. (1998) Stimulation of insulin release by repaglinide and glibenclamide involves both common and distinct processes. Diabetes 47: 345-351.

6. DeFronzo RA, Hendler R, Simonson D (1982) Insulin resistance is a prominent feature of insulin-dependent diabetes. Diabetes 31: 795-801.

7. Lombardo YB, Drago S, Chicco A, Fainstein-Day P, Gutman R, et al. (1996) Long-term administration of a sucrose-rich diet to normal rats: relationship between metabolic and hormonal profiles and morphological changes in the endocrine pancreas. Metabolism 45: 1527-1532.

8. Murakami N, Murakami T, Kadoya M, Matsuda H, Yamahara J, et al. (1996) New hypoglycemic constituents in "gymnemic acid" from Gymnema sylvestre. Chem Pharm Bull (Tokyo) 44: 469-471.

9. Sinsheimer JE, Rao GS, Mcllhenny HM (1970) Constuents from Gymnema sylvestre leaves. $V$. Isolation and preliminary characterization of the gymnemic acids. J Pharm Sci 59: 622-628.

10. Sinsheimer JE, Rao GS (1970) Constituents from Gymnema sylvestre leaves. VI. Acylated genins of the gymnemic acids--isolated and preliminary characterization. J Pharm Sci 59: 629-632.

11. Sugihara $Y$, Nojima $H$, Matsuda $H$, Murakami T, Yoshikawa M, et al. (2000) Antihyperglycemic effects of gymnemic acid IV, a compound derived from Gymnema sylvestre leaves in streptozotocin-diabetic mice. J Asian Nat Prod Res 2: 321-327.

12. Shanmugasundaram ER, Venkatasubrahmanyam M, Vijendran $N$ Shanmugasundaram KR (1988) Effect of an isolate from gymnema sylvestre, $\mathrm{R}$. Br. In the control of diabetes mellitus and the associated pathological changes. Anc Sci Life 7: 183-194.

13. Mall GK, Mishra PK, Prakash V (2009) Antidiabetic and hypolipidemic activity of Gymnema sylvestre in alloxan induced diabetic rats. Glob J Biotech Biochem 4: $37-42$.

14. Chatterji AK (2005) Therapeutic compositions: US Patent 6,946,151, 20.

15. Al-Romaiyan A, Liu B, Asare-Anane H, Maity CR, Chatterjee SK, et al. (2010) A novel Gymnema sylvestre extract stimulates insulin secretion from human islets in vivo and in vitro. Phytother Res 24: 1370-1376.

16. Mota ML, Thomas G, Barbosa Filho JM (1985) Anti-inflammatory actions of tannins isolated from the bark of Anacardium occidentale L. J Ethnopharmacol 13: $289-300$

17. Akinpelu DA (2001) Antimicrobial activity of Anacardium occidentale bark Fitoterapia 72: 286-287.

18. Alexander-Lindo RL, Morrison EYA, Nair MG, McGrowder DA (2007) Effect of the fractions of the hexane bark extract and Stigmast-4-en-3-one from Anacardium occidentale on blood glucose tolerance test in an animal model. Int J Pharmacol 3: 41-47.

19. Gilman AG, Rall TW, Nies AS, Tayer P (1990) Goodman and Gilman's the Pharmacological Basis of Therapeutics. 8th edn. New York. Pergamon Press: 1317-1322, 1463-1495

20. Sandouk T, Reda D, Hofmann C (1993) The anti-diabetic against pioglitazone increases expression of glucose transporters in 3T3-F442A cells by increasing messenger ribonucleic acid transcript stability. Endocrinology 133: 352-359.

21. Tschesche R, Hulpke H Fritz R (1968) Zur biosynthese von Steroid-Derivaten im Pflanzenreich-X, Phytochemistry 7: 2021

22. Choi KT (2008) Botanical characteristics, pharmacological effects and medicinal components of Korean Panax ginseng C A Meyer. Acta Pharmacol Sin 29: 1109-1118.

23. Roy D, Perreault M, Marette A (1998) Insulin stimulation of glucose uptake in skeletal muscles and adipose tissues in vivo is NO dependent. Am J Physiol 274: E692-699.

24. Spinas GA, Laffranchi R, Francoys I, David I, Richter C, et al. (1998) The early phase of glucose-stimulated insulin secretion requires nitric oxide. Diabetologia 41: $292-299$

25. Magnusson I, Rothman DL, Katz LD, Shulman RG, Shulman GI (1992) Increased rate of gluconeogenesis in type II diabetes mellitus. A $13 \mathrm{C}$ nuclear magnetic resonance study. J Clin Invest 90: 1323-1327.

26. Wajngot A, Chandramouli V, Schumann WC, Ekberg K, Jones PK, et al. (2001) Quantitative contributions of gluconeogenesis to glucose production during fasting in type 2 diabetes mellitus. Metabolism 50: 47-52.

27. Basu R, Chandramouli V, Dicke B, Landau B, Rizza R (2005) Obesity and type 2 diabetes impair insulin-induced suppression of glycogenolysis as well as gluconeogenesis. Diabetes 54: 1942-1948.

28. Hossain MZ, Shibib BA, Rahman R (1992) Hypoglycemic effects of Coccinia indica: inhibition of key gluconeogenic enzyme, glucose-6-phosphatase. Indian J Exp Biol 30: 418-420.

29. Gunjan M, Gunjan M, Jana GK, Jha AK, Mishra U (2010) Pharmacognostic and antihyperglycemic study of Coccinia indica. Int J Phytomed: 36-40.

30. Shibib BA, Khan LA, Rahman R (1993) Hypoglycaemic activity of Coccinia indica and Momordica charantia in diabetic rats: depression of the hepatic gluconeogenic enzymes glucose-6-phosphatase and fructose-1,6bisphosphatase and elevation of both liver and red-cell shunt enzyme glucose6-phosphate dehydrogenase. Biochem J 292 : 267-270.

31. Bonnefont-Rousselot D (2004) The role of antioxidant micronutrients in the prevention of diabetic complications. Treat Endocrinol 3: 41-52.

32. Baynes JW (1991) Role of oxidative stress in development of complications in diabetes. Diabetes 40: 405-412.

33. Machlin LJ, Bendich A (1987) Free radical tissue damage: protective role of antioxidant nutrients. FASEB J 1: 441-445.

34. Singh J, Kakkar P (2009) Antihyperglycemic and antioxidant effect of Berberis aristata root extract and its role in regulating carbohydrate metabolism in diabetic rats. J Ethnopharmacol 123: 22-26.

35. Valko M, Leibfritz D, Moncol J, Cronin MT, Mazur M, et al. (2007) Free radicals and antioxidants in normal physiological functions and human disease. Int $J$ Biochem Cell Biol 39: 44-84.

36. Sabu MC, Kuttan R (2002) Anti-diabetic activity of medicinal plants and its relationship with their antioxidant property. J Ethnopharmacol 81: 155-160. 
37. Karunanayake EH, Welihinda J, Sirimanne SR, Sinnadorai G (1984) Oral hypoglycaemic activity of some medicinal plants of Sri Lanka. J Ethnopharmacol 11: 223-231.

38. Im R, Mano H, Nakatani S, Shimizu J, Wada M (2008) Aqueous extract of kothala himbutu (Salacia reticulata) stems promotes oxygen consumption and suppresses body fat accumulation in mice. $\mathrm{J}$ health sci $54: 645-653$.

39. Yoshikawa M, Murakami T, Yashiro K, Matsuda H (1998) Kotalanol, a poten alpha-glucosidase inhibitor with thiosugar sulfonium sulfate structure, from antidiabetic ayurvedic medicine Salacia reticulata. Chem Pharm Bull (Tokyo) 46: $1339-1340$

40. Kirtikar KR, Basu BD (1918) Indian medicinal plants 582:1541.

41. Sekiguchi Y, Mano H, Nakatani S, Shimizu J, Wada M (2010) Effects of the Sri Lankan medicinal plant, Salacia reticulata, in rheumatoid arthritis. Genes Nutr 5: 89-96.

42. Bhat BM, C VR, D'Souza V, Manjrekar PA (2012) Antidiabetic and hypolipidemic effect of salacia oblonga in streptozotocin induced diabetic rats. J Clin Diagn Res 6: 1685-1687.

43. Augusti KT, Joseph P, Babu TD (1995) Biologically active principles isolated from Salacia oblonga wall. Indian J Physiol Pharmacol 39: 415-417.

44. Faizal P, Suresh S, Satheesh Kumar R, Augusti KT (2009) A study on the hypoglycemic and hypolipidemic effects of an ayurvedic drug Rajanyamalakadi in diabetic patients. Indian J Clin Biochem 24: 82-87.

45. Giron MD, Sevillano N, Salto R, Haidour A, Manzano M, et al. (2009) Salacia oblonga extract increases glucose transporter 4-mediated glucose uptake in L6 rat myotubes: role of mangiferin. Clin Nutr 28: 565-574.

46. Tezuka Y, Kikuchi T, Dhanabalasingham B, Karunaratne V, Gunatilaka AAL (1993) Salacenonal: A novel nortriterpenoid aldehyde of biogenetic significance from Salacia reticulata. Nat Prod Lett 3: 273-276.

47. Rajashree R, Parineetha PB, Ravishankar MV (2011) Effects of a mixture of Salacia reticulata $\mathrm{W}$. and Catharanthus roseus $\mathrm{L}$. extracts in streptozotocininduced juvenile diabetic rats. J Physiol Biomed Sci 24: 5-8.

48. Kishino E, Ito T, Fujita K, Kiuchi Y (2006) A mixture of the Salacia reticulata (Kotala himbutu) aqueous extract and cyclodextrin reduces the accumulation of visceral fat mass in mice and rats with high-fat diet-induced obesity. J Nutr 136: 433-439.

49. Mehra PN, Handa SS (1967) True Identity of Saptrangi Metab Abstract Casearia esculenta D, Casearia tomentosa D, Salacia chinensis D Hypo Glycemic. Ind J Pharm 29: 341.

50. Singh A, Duggal S (2010) Salacia species: hypoglycemic principles and possible role in diabetes management. Integr Med 9: 4

51. Deokate UA, Khadabadi SS (2012) Phytopharmacological aspects of Salacia chinensis. J Pharmacog Phytother 4: 1-5.

52. Scartezzini P, Speroni E (2000) Review on some plants of Indian traditional medicine with antioxidant activity. J Ethnopharmacol 71: 23-43.

53. Sanchez GM, Re L, Giuliani A, Nunez S, Davison GP, et al, (2000) Protective effects of Mangifera indica $L$. extract, mangiferin and selected antioxidants against TPA-induced biomolecules oxidation and peritoneal macrophages activation in mice. Pharmacol Res 42: 565-573.

54. Grover JK, Yadav S, Vats V (2002) Medicinal plants of India with anti-diabetic potential. J Ethnopharmacol 81: 81-100.

55. Williams JA, Choe YS, Noss MJ, Baumgartner CJ, Mustad VA (2007) Extract of Salacia oblonga lowers acute glycemia in patients with type 2 diabetes. Am J Clin Nutr 86: 124-130

56. Collene AL, Hertzler SR, Williams JA, Wolf BW (2005) Effects of a nutritional supplement containing Salacia oblonga extract and insulinogenic amino acids on postprandial glycemia, insulinemia, and breath hydrogen responses in healthy adults. Nutrition 21: 848-854.

57. Heacock PM, Hertzler SR, Williams JA, Wolf BW (2005) Effects of a medical food containing an herbal alpha-glucosidase inhibitor on postprandial glycemia and insulinemia in healthy adults. J Am Diet Assoc 105: 65-71.

58. Krishnakumar K, Augusti KT, Vijayammal PL (2000) Anti-peroxidative and hypoglycaemic activity of salacia oblonga extract in diabetic rats. Pharm Biol 38: 101-105.

59. Krishnakumar K, Augusti KT, Vijayammal PL (1999) Hypoglycaemic and antioxidant activity of Salacia oblonga Wall. extract in streptozotocin-induced diabetic rats. Indian J Physiol Pharmacol 43: 510-514.
60. Umamaheswari S, Mainzen Prince PS (2007) Antihyperglycaemic effect of 'llogen-Excel', an ayurvedic herbal formulation in streptozotocin-induced diabetes mellitus. Acta Pol Pharm 64: 53-61.

61. Ismail TS, Gopalakrishnan S, Begum VH, Elango V (1997) Anti-inflammatory activity of Salacia oblonga Wall. and Azima tetracantha Lam. J Ethnopharmacol 56: $145-152$

62. Huang TH, Peng G, Li GQ, Yamahara J, Roufogalis BD, et al. (2006) Salacia oblonga root improves postprandial hyperlipidemia and hepatic steatosis in Zucker diabetic fatty rats: activation of PPAR-alpha. Toxicol Appl Pharmaco 210: 225-235.

63. Huang TH, He L, Qin Q, Yang Q, Peng G, et al. (2008) Salacia oblonga root decreases cardiac hypertrophy in Zucker diabetic fatty rats: inhibition of cardiac expression of angiotensin II type 1 receptor. Diabetes Obes Metab 10: 574-585.

64. Jayawardena MH, de Alwis NM, Hettigoda V, Fernando DJ (2005) A double blind randomised placebo controlled cross over study of a herbal preparation containing Salacia reticulata in the treatment of type 2 diabetes. J Ethnopharmacol 97: 215-218.

65. Yoshikawa M, Morikawa T, Matsuda H, Tanabe G, Muraoka O (2002) Absolute stereostructure of potent alpha-glucosidase inhibitor, Salacinol, with unique thiosugar sulfonium sulfate inner salt structure from Salacia reticulata. Bioorg Med Chem 10: 1547-1554

66. Oe H, Ozaki S (2008) Hypoglycemic effect of 13-membered ring thiocyclitol, a novel alpha-glucosidase inhibitor from Kothala-himbutu (Salacia reticulata). Biosci Biotechnol Biochem 72: 1962-1964.

67. Yoshino K, Miyauchi Y, Kanetaka T, Takagi Y, Koga K (2009) Anti-diabetic activity of a leaf extract prepared from Salacia reticulata in mice. Biosc Biotechnol Biochem 73: 1096-1104.

68. Im R, Mano H, Matsuura T, Nakatani S, Shimizu J, et al. (2009) Mechanisms of blood glucose-lowering effect of aqueous extract from stems of Kothala himbutu (Salacia reticulata) in the mouse. J Ethnopharmacol 121: 234-240.

69. Kishino E, Ito T, Fujita K, Kiuchi Y (2009) A mixture of Salacia reticulata (Kotala himbutu) aqueous extract and cyclodextrin reduces body weight gain, visceral fat accumulation, and total cholesterol and insulin increases in male Wistar fatty rats. Nutr Res 29: 55-63.

70. Venkateswarlu V, Kokate CK, Rambhau D, Veeresham C (1993) Antidiabetic Activity of Roots of Salacia macrosperma. Planta Med 59: 391-393.

71. Kishi A, Morikawa T, Matsuda H, Yoshikawa M (2003) Structures of new friedelane- and norfriedelane-type triterpenes and polyacylated eudesmanetype sesquiterpene from Salacia chinensis LINN. (S. prinoides DC. Hippocrateaceae) and radical scavenging activities of principal constituents. Chem Pharm Bull (Tokyo) 51: 1051-1055

72. Yoshikawa M, Pongpiriyadacha Y, Kishi A, Kageura T, Wang T, et al. (2003) [Biological activities of Salacia chinensis originating in Thailand: the quality evaluation guided by alpha-glucosidase inhibitory activity]. Yakugaku Zassh 123: $871-880$

73. Morikawa T, Kishi A, Pongpiriyadacha $\mathrm{Y}$, Matsuda $\mathrm{H}$, Yoshikawa $\mathrm{M}$ (2003) Structures of new friedelane-type triterpenes and eudesmane-type sesquiterpene and aldose reductase inhibitors from Salacia chinensis. J Nat Prod 66: 1191-1196.

74. Rastogi R, Mehrotra BN (1979) Compendium of Indian medicinal plants Vol2;1979, CDRI \& NISCOM: Lucknow, New Delhi;600-601.

75. Tewari NC, Ayengar KN, Rangaswami S (1974) Triterpenes of the root-bark of Salacia prenoides DC. J Chem Soc Perkin 1 1: 146-152.

76. Guo ZH, Xi RG, Wang XB, Wu LJ, Gao HY (2009) A new trincallane derivative from Salacia hainanensis Chun et How. Yao Xue Xue Bao 44: 1123-1126.

77. Guo ZH, Huang J, Wan GS, Huo XL, Gao HY (2013) New inhibitors of Îtglucosidase in Salacia hainanensis Chun et How. J Nat Med 67: 844-849.

78. Yuan G, Yi Y (2005) [Studies on chemical constituents of the roots of Salacia hainanensis]. Zhong Yao Cai 28: 27-29.

79. Setzer WN, Holland MT, Bozeman CA, Rozmus GF, Setzer MC, et al. (2001) Isolation and frontier molecular orbital investigation of bioactive quinonemethide triterpenoids from the bark of Salacia petenensis. Planta Med 67: 6569.

80. Deepa MA, Narmatha Bai V (2004) Antibacterial activity of Salacia beddomei. Fitoterapia 75: 589-591. 